\title{
Moments of alignment between devolved political ideology and policy design: the case of Wales
}

\author{
Sioned Pearce,* Christala Sophocleous, Helen Blakely and Eva \\ Elliott \\ Cardiff University
}

\begin{abstract}
The devolution of power and responsibility from central to sub national levels of governance over the past half century marks a paradigm shift in forces shaping social policyacross much of Western Europe. Scholarship in this field is often concerned with a binaryanalysis of before and after the advent of devolution, with insufficient attention paid to transitory changes over time. Through attention to Wales' flagship community regeneration programme, Communities First, a striking instance of divergent devolved social policy, we highlight the need to attend to the dynamics of devolution across time. Drawing on empirical data charting the programme's conception, implementation, evolution, distortion and eventual demise, we argue that a moment of alignment between ideology and policy design was visible at conception but eroded over 16 years, as the programme increasingly came to bear the hallmarks of neoliberalism. Using this case study, we consider the extent to which newly devolved states can implement ideological policy visions that resist the restraints put upon sub-state governance on the one hand and forces of central state ideologies and logics on the other.
\end{abstract}

Keywords: devolution, social policy, community, ideology, policy design.

\section{Introduction}

Devolution of power from central to sub national levels of governance marksa paradigm shift in the dynamics shaping social policy across much of Western Europe during the last half century. Studies examining the impact of devolution on social policy often compare divergences between sub-states (Birrell, 2009), specific constitutional arrangements and their impact before and after devolution (Jones et al., 2005; Jones and MacLeod, 2004; Roberts and Devine, 2003). While conceptually useful for understanding decentralisation, few such frameworks capture alignments, or indeed misalignments between ideology and policy design as they unfold over time within devolved spaces. Drawing on the case of Wales, and specifically the flagship community regeneration programme Communities First, we address this dimension by charting the programme's history; from an initial, albeit momentary, alignment between devolved ideology and policy design to a dissonant implementation strategy, which, over time, came to bear the hallmarks of neoliberalism. The study identifies some characteristics which are often associated with, but not reducible to, the concept of neoliberalism; such 
as profit orientated, market mediated logic leading to competitiveness and the rise of auditing across policy fields (Sum and Jessop, 2013; Power, 1999).

Here we contribute to the study of social policy making in a devolved context (Birrell, 2009), and specifically the extent to which newly devolved states can implement ideological policy visions that resist the restraints put upon sub-state governance on the one hand and forces of central state ideologies and logics on the other. We do so by providing a descriptive device which we term a moment of alignment, for better understanding of devolved, social policy transition over the long-term and in the context of global territorial rescaling. While territorial rescaling, particularly at regional level, is often viewed as a route towards welfare retrenchment (Greer, 2010; Gallego and Subirats, 2012; Jones, 2015; Ohmae, 1995; Sellers and Lidström, 2007; Sheeley, 2012; Vampa, 2014), egalitarian alternatives to market-driven visions of devolved regional policy-making do occur, often focusing on the inclusion of marginalised groups or places.

Welsh devolved social policy is one such instance. However, the political vision for social policy in Wales hinged on an initially weak constitutional arrangement and faced challenges from opposing central UK government policy. Using the example of Communities First, which at its formation was conceptualised as a community-ed regeneration programme, and ran from 2001 to 2017 in the most deprived places in Wales; we argue that the Welsh Government's vision was subject to and affected by internal-past and external-contemporary pressures from opposing ideologies. Approximately 150 geographical communities, with populations of between 1,500 and 11,000 people and ten communities of interest including ethnic minority and disability focused communities, were included in the programme. Over 16 years it cost the Welsh Government approximately 300 million pounds, 60 per cent of which was spent on core revenue such as staffing, employing around 800 people mostly as community development workers (Welsh Government, 2006; National Assembly for Wales, 2017). Communities First areas were chosen using the Welsh Index of Multiple Deprivation (2001), a matrix updated every four to five years, which reports on concertation of deprivation at a local level. Designed by the then National Assembly for Wales ${ }^{1}$ Communities First was the flagship, devolved, Wales-wide programme to address inequality and promote social justice. The programme went through several significant revisions before its end was announced, in 2017 , on the basis that '... poverty remains a stubborn and persistent challenge' (BBC, 2017), with central funding terminated in April 2018; eight years after the beginning of UK-wide austerity measures.

Inclusion of marginalised groups was central to the programme design, based on the principles of participatory democracy. Here we make our argument by tracing the history of Communities First, detailing its revisions and identifying a sharp, and then incremental move away from a moment of alignment between Welsh political ideology and policy design, and a commitment to participatory democracy. The notion of a moment is a descriptive device to frame and examine the complex and shifting tensions and interrelations characterising the process of devolution by the 'freezing of chronological time sequence to hold up an event to close scrutiny' (Callon, 1986 in Hamilton, 2011: 60 ). The moment used in this way allows us to attend to the processes and practices associated with the 'ongoing territorialization of social policy' (Chaney and Wincott, 2014: 774), or the rescaling of social policy responsibilities and powers upward, downward and outward to supra-and sub-national levels of government

\section{Method}

Our analysis of the moment of alignment between ideology and policy design originates from six separate research studies in the field of devolved social policy, completed or 
being carried out by the authors ${ }^{2}$ (Blakely, 2011; Pearce, 2012; Sophocleous, 2009; 2014: Elliott et al., 2020). In total it draws upon 49 qualitative interviews carried out in 2008/9 and 2016/17 and two ethnographic studies undertaken from 2008/10 and 2010-2011. The findings presented in this paper, however, are not a synthesis of the separate studies, but have been developed through a form of meta-analysis. The synthetic theorisation (Kuehn and Corrigan, 2013) of a moment of alignment and subsequent divergence has emerged through the authors' collaboration. Methodologically the ideas presented here were developed through an on-going dialogue between researchers on their individual studies, emerging iteratively as a new substantive analysis, beyond that of any single study. This process has reshaped and reworked the study-specific, but interrelated, findings to create new insights that are strengthened by this process. Additionally, the papers' genesis was made possible through two aligned factors. Firstly, that of time, marked by the announcement of the phasing out of the Communities First programme, which stimulated debate across Wales. Secondly, that of academic space, as the authors are co-located in a research institute hosting an extensive civil society programme, which facilitates the sharing of data and ideas.

Each of the six studies has a distinct focus but analytically noneaddressed a moment of alignment. Its emergence through collectiveanalysis followed the identification of two recurring and overlapping themes. Firstly, all six studies captured a notable change in Welsh political ideology over time, visible in policy rhetoric and intent on deploying and invoking shifting constructions of community over the life of Communities First Specifically, policy rhetoric shifted away from initial ideals of participatory and community-led policy design and towards a top down model of delivery. Secondly, and relatedly, all six studies put forward a critique of the programme's implementation, evaluation and impact over time. This stimulated further analysis of the dynamic between implementation practices and changes in the rhetorical positioning of communities over the life span of the programme. In turn, this brought into relief questions about the capacity and limits of devolved governance in the field of social policymaking. This paper adopts an innovative approach that builds on a collective resource, affording novel insight for social policy and sociological enquiry into the salience and impact of large and complex policy programmes for particular socioeconomic contexts.

\section{Moments of alignment}

\section{Devolution: creating the Welsh state}

It is possible to understand the challenges for devolved policymaking in Wales by looking at its first decade and its rapidly shifting constitutional arrangements. Before the formal separation of executive and legislative arms within the Welsh Government in 2007, Wales had no independent executive powers in law, meaning the Welsh Assembly Government (WAG) essentially functioned as a large local authority (Richard Commission, 2004). The Silk Commission (2012) on devolved powers reconfirmed the restrictive limitations of Welsh devolution by recommending tax raising powers and budgetary control based on the argument that 'the current arrangements ... do not meet the requirements of a mature democracy and are anomalous in an international context' (Silk, 2012: 9). Despite weak constitutional arrangements, particularly in terms of income generation, devolution in Wales has provided 'windows of opportunity' (Taylor 2003) for divergent social policy narratives and practices, many of which have taken a broadly social democratic approach (Drakeford, 2006; Chaney, 2002; Mooney and Poole, 2004; Royles, 2007; Birrell, 2009; Chaney and Wincott, 2014; Poole et al., 2016). 
Welsh Labour, the party in power since 1999 (either as the sole party or in coalition), sought to develop a policy agenda notably divergent to that of the UK government (Chaney and Drakeford, 2004). The ideological basis of this distinctiveness is threefold: universalism as opposed to means testing; equality of outco me in place of 'equality of opportunity'; and cooperation for the common good rather than competition (Chaney and Drakeford, 2004). Oft cited examples include the provision of free school breakfasts, free swimming, prescriptions and hospital parking (Chaney, 2016). The Welsh approach to public service provision and rejection of significant private sector involvement was also a significant point of divergence. As a result of this distinct agenda, post-devolution Wales is often held up as promoting a politics quite different to that of England. Indicative of this sentiment was then Welsh First Minister (2000-2009) Rhodri Morgan's invocation of the notion of clear, red water heralding a key separation between the Welsh and English political ideology and approaches to policy. As Davies and Williams(2009) put it:

"The novelty of the 'clear red water' speech was that, whereas these polices had previously been offered as piecemeal, pragmatic measures, they were now presented as part of an overall strategy of de-commodification" (ibid.:49)

However, an examination of social policy focusing on community presents a more complex picture. During the late 1990s the notion of developing communities as the key to tackling both inequalities and poverty emerged in the UK. Initiatives marking the reemergence of state policy in the community development tradition include both Wales' Communities First and England's New Deal for Communities. Thus, while Welsh Labour strove for ideological divergence from New Labour, the origins of policy design were nonetheless influenced by forces from England (Dicks, 2014).

The idea of community and the role ascribed to it within political discourse, although highly problematic for both, differs markedly between Communities First and New Deal for Communities. The outcomes of New Labour's conceptualisation of community, drawn from Etzioni's brand of communitarianism (1993, 1996a; 1996b) and developed for policy implementation most notably by Giddens (1998; 2000), has been subjected to extensive and penetrating critique, particularly for the way it seeks to recast the relationship between the state and the individual. Critics have highlighted its neoconservative underpinnings and moralistic tone (Davies, 2002; Driver and Martell, 1997, 1999; Fairclough, 2002; Hale, 2004; Levitas, 2005; Lund, 1999; Newman, 2001; Prideaux, 2005; Schofield, 2002; Taylor, 2003). This Third Way approach was enacted in policy through discourses of participatory policymaking and community engagement, and most frequently held together through narratives of working together and partnership (Armstrong and Wells, 2006; Glendinning, Dowling and Powell, 2005; Sullivan and Skelcher, 2002). It is im portant to note, however, that much of this critique has been retrospective and that initially the ideas framing New Deal for Communities were largely embraced and viewed as a positive policy step by many. The Labour Party in Wales sought a subtly different basis for the relationship between the state and society, emergingalongside more broadly social democratic principles, and deriving from ideas of collective, community-led action. This is captured in the emerging tripartite arrangements for social dialogue and the relative prominence of trade unions in Wales (Beynon, Davies and Davies, 2012), as well as in early constructions of community within the Communities First programme (Adamson, Dearden and Castle, 2001). In order to elucidate its direction, we turn first to the ideological underpinnings of Communities First and specifically invocations of community in the initial phase of devolution. 


\section{A moment of alignment: ideology and policy design}

Designed by a Welsh-based intelligentsia (Adamson, Dearden and Castle, 2001), Communities First was conceived as a community-led regeneration programme, in place to mitigate the effects of deprivation. Crucially it was not intended to tackle what were understood to be the structural determinants of poverty in Wales (ibid). While this was a state sponsored intervention, the establishment of local forms of participatory governance were intended to emerge from and build upon existing community development traditions. The genuine commitment from within Government to incorporating community-led principles can be seen in the crucial role played by Adamson and Castle, who were independent consultants with academic backgrounds and expertise in community development and grass-roots oriented regeneration. They were to be principal agents in designing the programme. The programme's early focus was on capacity building among local people and the development of collective forms of participation; conceptually community was constructed as a place-based collective of people with agency and power. Its authors explicitly attempted to move away from the notion that responsibility for deprivation lay with communities; rather members were seen to have a valuable perspective within a conducive, operational policy environment:

“... it is essential that the voice of the community is clearly heard from inception and that the structures established allow the community level of participation to grow as community capacity grows" (Adamson et al., 2001:17)

The programme was to create a forum for local voices, which would be heard by the newly established Assembly (ibid., 2001). This inclusive approach was seen to be particularly advantageous for those experiencing the complexand multifaceted im pacts of long-term, systemic poverty, who were framed as the experts in terms of understanding the needs of their communities. Closely linked with the promise of a more democratic interface between state and society through devolution, this space for community-led regeneration was enshrined in the institutional framework of the programme.

Under the auspices of Communities First, targeted localities were required to establish a partnership to act as the principal vehicle for local community development activity. Each partnership was to be formed on the basis of what become known as the three thirds principle, in which a third of its membership was to be made up of local community members, a third from statutory bodies and a third from local voluntary groups and businesses. These were to be community-led partnerships, afforded the status of institutional instruments (Bristow et al., 2008), and vested with the authority and responsibility 'to lead in taking forward the programme in their areas' (WAG, 2002b: 23). The concept of partnership was constituted within Communities First's accompanying guidance, as the substantive driver of programme development and implementation. It was a non-negotiable institutionalised principle of collaboration, to ensure that progress could only be made through deliberation and consensus. This framework is noteworthy for the way it conferred institutional recognition to the community as the key partner of the regeneration process, theoretically eliminating any possible exclusion from decision-making processes or rendering local people passive recipients of other actors' plans. However, also noteworthy is the fact that policy intent was not augmented by legal or regulatory structures to reinforce, protect and guarantee the three thirds principle within partnership working; a significant gap given that sharing partnerships did not mean sharing power in practice (Pearce, 2012).

There was a sense in which this programme was different, '[there was a] feeling in the Assembly that this was a radical programme' (cited in Sophocleous, 2011: 110). This community development approach to delivering social policy (WAG, 2000; 2001), and 
accompanying conceptions of partnership, participation, and community leadership were central in the Communities First narrative and aimed to improve confidence and self-esteem from the bottom up. As the First Minister explained:

“...During a recent Plenary statement on Communities First ... Edwina [Hart] announced that $£ 83$ million would be spent over the next three years. That money is not for intermediaries to disperse; community groups will have direct access to it. In order for communities to be successfully regenerated, the approach must be bottom-up, not top-down. Community leadership must also be encouraged. That involves people living and working in the community, not intermediaries." (First Minister2001: 19)

To put Communities First into context, the explicit commitment to bottom up community-led regeneration with its tripartite structure was arguably subtly different from the narratives of community engagement and participation within New Labour's New Deal for Communities programme, promoting community engagement and putting communities 'at the heart of regeneration initiatives' (Beatty, et al., 2010; Geddes, 2006; Lawless et al., 2009: 7). While in England 'efforts to engage residents and to enhance the capacity of the local community' were made, this was secondary to placebased outcomes (ibid., 2009: 7) and 'communities werefelt to be 'shoehorned' into local policy initiatives according to central government guidelines' (Imrie and Raco, 2003: 27 in Pill, 2012). At the outset similarities between the two programmes were visible, the most obvious being the prominence of 'community' as a concept and the emphasis on communities taking a lead role. However, there were also significant divergences which increased as the respective programmes progressed. In terms of scale, breadth and concertation, New Deal for Communities was bigger, better funded and put its emphasis firmly on Regeneration, not Community Development, in terms of programmeapproach. ${ }^{3}$ One of the six New Deal for Communities objectives on partnership working was involvement of delivery agents such as police, schools and JobCentre Plus, but not communities, despite the initial objective of 'putting communities in the driving seat' With these differences to consider it is not possible, nor are we aiming to, compare Communities First and New Deal for Communities, but rather to highlight the ways in which core elements of each reflect the difference in policy approach taken by Welsh and New Labour at the time. To summarise, signalling the aspiration for a new kind of settlement between the Welsh state and the people, Communities First was perhaps more far reaching in its ambition to establish new forms of participatory democ racy than its English counterpart. Indeed, its challenge to traditional modes of legitimacy and accountability was well recognised by elected representatives. One Minister explained:

"I think the thirds, thirds, thirds is there to establish the legitimacy of the partnerships, ... well this is not direct democracy let's not kid ourselves - we're not having the community turn up at an annual general meeting and electing its representatives to do this ...nor is it based on traditional representational democracy, so it's not councillor, Assembly Member or MP whatever, taking a lead in it. So you have to have ... some constitutional basis for the partnerships that allows people to recognise that there are good reasons for the other people to be around the table, if you're going to take these things forward. And [the] hope [is] that the third, third, third, approach [has] gone some way towards that" (cited in Sophocleous, 2009: 54).

This desire to establish local legitimacy within and between communities, the statutory sector and the third sector (the thirds); and between local partnerships and the devolved state was a marked departure from the status quo. The challenges of this approach were well recognised by its architects, and account in large part for their 
recommendations in relation to the initial implementation of the programme (Adamson et al., 2001). Acknowledging the highly variable levels of community development tradition in many of Wales' poorest communities, they proposed that Welsh Government take five to 10 years to roll out the programme, incrementally beginning in 20 to 30 localities which had a strong history of community development and, crucially, the capacity to build on existing infrastructures. From there, it was envisaged, capacity building would lead to a growth in area-based community development expertise which in time could be rolled out to other communities. This commitment to the central tenets of community development was integral to the approach since:

"Parachuting large sums of moneyand development into unprepared communities will not be an effective mechanism for regeneration... a long-term, incremental development process must occur" (Adamson et al., 2001:29)

At its conception then, Communities First was shaped by a bold and divergent policy rhetoric subtly different to that of English community regeneration policies. Here we show it is possible to trace a thread of strong political commitment to the transfer of power from state to community, orchestrated by academics, underpinned by their recommendations and supported by policymakers. However, in time and in practice this idealistic, social democratic vision became moreakinto the "downscaling and offloading of austerity politics' from state to community (Pill and Guarneros-Meza, 2017); as we discuss in the following section.

\section{Derailing and disjuncture: programme implementation}

As we have seen, there was considerable alignment between the ideologically driven aspirations of Welsh Government and the policy design of Communities First. However, over time this alignment was eroded. Here we explicate this process, highlighting key points of disjuncture as the programme was implemented. We identify three key elements of programme implementation that initiated and then cemented the misalignment with political aspirations. In turn, this section considers firstly, initial programme roll-out which transformed Communities First from an incremental developmental initiative to a Wales-wide scheme. Secondly, we address the logistics of the programme by attending to funding mechanisms, the role of local authorities and partnerships. Finally, we consider the issues of accountability and the introduction of measurement matrixes, which shifted power from local communities upwards to the national Welsh Government.

\section{Initial implementation: the Big Bang}

In a departure from the recommendation for a slow, incremental and developmental roll out, Minsters made a late decision to implement the programme rapidly over the course of a few months in each of the 100 communities with the highest concentrations of social deprivation according to the Welsh Index of Multiple Deprivation. Along with a number of communities of interest and pockets of deprivation, civil servants were directed to oversee the simultaneous development of 142 Communities First partnerships. This rapid and widespread implementation negateda consultation process carried out by local authorities to rationalise area selection based on community development capacity:

"I saw that the council put time into this, consulted the communities, consulted voluntary sectors, local organisations put them together, then staff read them in 
turn at this meeting where $X$ civil servant then went 'here's $X$ area, they're out, they're in, they're out, $X$ area, they're out, they're in'... someone said 'I thought we're meant to be commenting on these?' and ... [the senior civil servant] said 'Oh no, the minister has decided, it's the top 100'" (Voluntary Sector worker cited in Pearce, 2012:230)

Colloquially termed the big bang, this move had significant implications for the programme. The inclusion of communities based on a quantitative calculation of the extent of their deprivation, rather than their capacity to adopt a community development approach, meant many targeted communities entered the programme without strong community resources or local institutions upon which to build. Intervieweesacross all six studies expressed strong opinions about the damaging nature of this decision, which was seen as undermining the underpinning values and fundamental principles of the programme. As this respondent elaborated:

"So we're not anymore, talking about, actually trying to say that Communities First is an approach - (...)-it's not necessarily going to work everywhere in the same way - that doesn't mean that everywhere doesn't need something - but this is an approach that will work where, if you've already got a bit of a decent relationship between the local authority and the people you're going to work with, if they have done some, or can talk about some, community developments that they have done in their area before, then - clearly they understand what this is about - then, that's the right sort of starting point, But if you'restarting from absolutely nowhere - then don't do it!" (original emphasis) (National Voluntary Officer cited in Sophocleous, 2009: 45)

In addition to negating the underpinning values of the programme this 'big bang' approach created a plethora of practical difficulties for progra mme implementation. For the sake of brevity, we give two examples here: first is the paucity of suitably experienced and qualified individuals from which to recruit partnership coordinators and development staff, leading to inexperienced stafftaking on co mplex development tasks, and perhaps inevitably, high rates of staff turnover in the earlyyears. Secondly, the 'big bang' approach failed to take account of the fact that the Welsh civil service was both too small and ill-equipped to oversee the implementation of a national programme, which had increased five-fold overnight (Osmond, 1999).

Collectively these and other factors had significant impacts on the extent and strength of community involvement in the development of the partnershipsand decisionmaking within them. The speed of implementation and the political imperatives to establish partnerships also created a de facto shift in developmental approach to favour local authorities as key agents in local programme implementation.

\section{Logistical challenges and sectoral tensions}

Given the imperative to establish partnerships quickly in order to secure programme funding, localities without a history of community development became heavily dependent on the existing statutory sector structures (Pearce, 2012). The culture within many of these structures was not conducive to community involvement and lacked capacity for and experience of community development. Over time power imbalances between local communities and statutory groups were further accentuated through a growing emphasis on public service provision delivered through the partnerships. Many Communities First staff were directly line managed by local authority staff, for exam ple, leading to conflicts in accountability for those working alongside community members. This was also reflected and enabled in the mechanisms for funding allocation, which 
invariably favoured the long-standing systems and bureaucratic structures of the statutory partners over smaller community and voluntary groups. In addition, and compounding statutory dominance within partnerships, funding for most local partnerships was held by local authorities as the designated Grant Recipient Body (GRB). Presented as an arbitrary title, the partnership GRB status held a great deal of symbolic and real power over operations and decision-making(Pearce, 2012).

“... [becoming our own GRB] ... has speeded things up for us ... if I send in a claim to WAG now... I get a fourday turnaround, the money is in the bank, prior to that .... it would be several months before we saw the money" (Community development worker in partnership with independent GRB cited in Pearce, 2012: 191)

While local practice varied considerably across Wales, the cumulative consequences were manifold, leading to widespread criticism from voluntary and community agents, whereby the statutory sector was viewed as using the programme to expand its own provision, based on statutory understandings of need, rather than supporting community-led regeneration or development (Pearce, 2012). This was particularly acute where the local authority served both as GRB and employer of staff, as highlighted by this respondent:

“..ere... you could put it kindly and could say they are confusedabout their roles as GRB and employer ...because they have a role to play as a service provider etc. etc., but they raise things which ought to be raised for discussion with the Partnership, they raise it with their employees as a ... er ... boss-servant thing and exert influence that way, and where things are not running smoothly they can prevent staff giving support to the Partnership, in the way that ought to be happening in community development terms" (National Voluntary Organisation cited in Sophocleous, 2009: 47)

Seven years into the programme its lead architect, Adamson, argued that while community participation was evident, both dominant and unresponsive statutory partners were limiting its potential (Adamson and Bromiley, 2008). The three thirds principle of partnership working was not working because, nominally, equal partnership did not mean equal power.

At this time the global economic recession of 2008 led to externaleconomic pressure for all Welsh organisations, which in turn brought about a slower, and arguably deeper, erosion of the programme'sideological beginnings. The second phase of the programme, Communities Next ${ }^{4}$ (Children in Wales, 2008), cut and centralised funding from 2009 onwards. While partnerships remained key at this point, the new focus on outcome measures, which replaced capacity building in the policy rhetoric, shifted power upwards towards local authorities and Welsh Government as arbitrators of acceptable outcomes.

The most significant revision of the programme took place in 2011; this introduced local authority led clusters made up of a number of (former) Community First partnerships. Receipt of funding at this time became conditional upon community involvement, a strategy which implicitly denoted the dominance of statutory partners as the lead applicant for funding:

"[the local authority] is using Communities First funding as a way of controlling the area ... I mean ... a lot of externally advertisedjobs for the partnership are given to internal candidates at the local authority..." (Community development worker cited in Pearce, 2012:191) 
Most significantly, the new guidance issued no requirement for there to be local partnerships and the institutional instrument of the thirds was omitted, and the idea of community-led work erased. In this sense any policy connection to the original community development principles advocated by Adamson, Dearden and Castle (2001) had been severed.

\section{Accountability and measurement}

The direction and operationalisation of accountability changed considerably during the years of the Community First programme. Reference to indices of successful programme implementation is notable by its absence in the early years. Rather the early guidance focuses on outlining the process of development, instructing local partnerships to develop locally agreed action plans, with a strong emphasis on building local community capacity. Specifically, notions of accountability can be seen in three particular forms in the earlyyears of the programme. The first relates to the audit issue of accounting for the expenditure of public funds; the second to the more complex issue of implementing action plans; and the third concerns accountability to communities. The first two can be seen in the extract below from the 2002 WAG Guidance to local authorities.

"Communities First Partnerships will need to put in place a process which provides clear accountability for any public money held by or for it and a structure for implementing Community Action Plans." (WAG, 2002a: 13)

Seen from the vantage point of history, the limited nature and vagueness of the instruction to establisha structure for implementing the action plans appears naïve, and perhaps demonstrates something of the immaturity of the devolved institutions of Welsh governance at the time. It does, however, encapsulate the zeitgeist of the programme, its focus on communities defining their own priorities and the role of local authorities to ensure it happens. This leads to the final evocation of accountability in the early days of the programme: accountability to community as key partners in the partnerships. This once again centred the role of communities and the process of community development in the programme design as a space for participatory democracy, which ultimately marked it as unique.

The move to an increased emphasis on performance targets, data collection and internal and external monitoring, alongside the introduction of explicit, prescriptive areas of focus including health, environment, education and crime, while incremental, was marked by two points of significant step change. The first came with the refocusing of the programme in 2008 :

“... what we have done, not least as part of the review programme is make a very definite shift away from a focus on capacity building in favour of a focus on delivering outcomes, as the primary focus of the programme." (Civil servant interview, 2009.

The changes in accountability systems made during this period could be seen as an attem pt to tighten and make more explicit the achievements of the partnerships. While reporting requirements were marked by more prescriptive frameworks, it is possible to identify, at least at a discursive level, a commitment to the ideas of community development. The tensions identified by respondents revolvedaround the interpretation of practice, as we see in this quote from a representative of a national third sector organisation: 
"I don't have a problem with the outcomes focus; community development is about change, and if you're about achieving change you have to have some sort of expression of what it is you are trying to change - that's legitimate. I think $X$ (civil servant) understands that - what I'm not sure is when it comes down to the practice of actually looking at an Action Plan and deciding whether they're (WAG) going to give money for it - whether his staff understand that. And I think - we have had conflicting views $-X$ will say in a training session 'yes outcomes are very broad' - (....) - but then when they have their visit after the monitoring report has gone in - the WAG staff say, 'what's this stuff - it doesn't really show that you're achieving anything'." (National Third Sector Interview, Sophocleous, 2009)

The final erosion of accountability as located within communities and the partnership came in the 2011 programme redesign. The introduction of clusters and the refocusing of the programme around the three themes, health, education and employment, also saw the introduction of an outcomes-based accountability framework. This saw the introduction of highly prescriptive targets and measures, which in effect tightened the spaces in which community-led decisions could be made. ${ }^{5}$ Here we also see the manifestation of a centrally-driven move towards capturing success through numbers which demanded focus on measurable outcomes, akin to those imposed on a wide range of social policy interventions by the mandate of New Public Management auditing (Hoggett, 1996; Hood, 1991; Rhodes, 1997; Vedung, 2017). This drive to reverse accountability emerged in part due to critiques of the programme within externally commissioned evaluation and internal monitoring processes:

"I mean it's very difficult to say for sure but you can sort of infer that all of that [change to the monitoring processes] arose as a consequence of this stream of external reports as well as our internal outcome evaluation. Erm so in that sense it was a direct response to the research evidence I think, erm and I suppose just experience of running the programme in such a large number of areas in the past, small areas." (Civil Servant, interviewed for Pearce, Elliott and Frayne study, January 2017)

It is noteworthy, however, that much externally commissioned research highlighted the innate difficulty of measuring or quantifying community development work, while simultaneously critiquing the programme for not performing against national indicators of poverty (Cambridge Policy Consultants, 2006; Coleman, 2009; Hincks and Robson, 2010; Ipsos MORI and Wavehill Consulting, 2015; Wavehill Consulting, 2007). This is seen in the following quotes:

“...it is not possible to undertake a detailed quantified 'top down' analysis of the value for money of the CF programme..." (AMION et al., 2011:110)

And

“...no firm conclusion is drawn about the extent to which Communities First is achieving its aims. Indeed, an assessment of its outcomes is likely to be hampered by the availability of beneficiary data and robust monitoring information and by the design of an area based intervention to achieve individual-level change." (Ipsos MORI, 2015:88)

The overriding interpretation of the change, and its impact, is the hiddenand reduced value of community development work. As programme accountability to the community became community accountability to the Welsh Government, the way in which the stories 
of success and failure were constructed reduced in scope, detail and richness, hiding much of the substantive work undertaken. This process of appearing compliant (Rhodes, 2011) created two kinds of work, one official and reported to WG and the other which held on, despite all efforts to the contrary, to the community development principles of the original programme. As the following respondent explains:

"Well anyway \{sighs\} so yeah, that was all about um, us saying to [the monitoring body], we'll get so many people, we'll get them to with this, whatever, and we had to churn out certificates and do all that. So we did that, but because we were experienced and knew that, that was something, but the other stuff that we supported people's lives with, was going in around that, but we never ... they never asked us about that. So, we never told them. But the real support went around underneath the wire really." (Community Development Worker, interviewed for Pearce, Elliott and Frayne study, 2017)

This process of measuring successthrough numbers which became more entrenched over time had detrimental impacts upon the day-to-day delivery of community development work, as well as upon the sustainability of community projects and the wellbeing of development workers themselves:

"Yeah, and the pressure of Communities First in various ways has inhibited our ability to fundraise, be it from the lack of council or lack of time. Erm, and it's also erm, it's anothersort of unfortunate thing that comes out of Communities First it's not ... it doesn't give you, in the same way it doesn't give you time for reflective practice, it doesn't give you thinking time either, you know. You've got to really struggle in your working day to find the time to think things through, you know. And that's not good, it's not healthy, that's not, it's not healthy foryour mind, you know because you're just turned into like a robot, you know, just delivering, and delivering all the time." (Community Development Worker, interviewed for Pearce, Elliott and Frayne study, 2017)

The ideologically driven, bold and divergent approach characterising Communities First's policy design was derailed from its moment of alignment at implementation, away from its ambition for universalism, equality and cooperation. The community-led principles of capacity building, empowerment and partnershipenshrined in design were replaced with outcomes, results and accountability (to Government) over 16 years. A stark contrast between changes to the programme and reflections from research participants within it, therefore, highlight both the moment and its disappearance.

\section{Concluding discussion}

The programme's purpose altered dramatically at implementation, which in turn altered the benchmark against which success was defined, from a focus on process to outcomes, alongside growing internal and external political and economic pressures. Over time, the impact of this derailment led to communities being held accountable for the delivery of an increasingly state-led agenda, an approach far closer to New Labour's Third Way than to the vision set out by Welsh Labour at the advent of devolution (Dicks, 2013). Allocation of funding based on measures of deprivation (the 'big bang' approach), rather than on existing, historically rooted community development capacity (Adamson, Dearden and Castle, 2001), curtailed the building of community development capacity. Further, and subsequent, Government preference for local authority led delivery and the 
introduction of a metrics approach to measuring the value of community development work eventually led to the severing of ties between the vision and its realisation.

Motivationsfor this change cannot, however, be explained away by a growth over time in Welsh Governmententhusiasm for trends often associated with, though not reducible to, neoliberalism, such as competitiveness, individualisation and an emphasis on metric measures of success. Neither is it fair to say that the New Deal for Communities programme was motivated by these same trends. However, over the course of 16 years, adoption of these characteristicscan be seen as a complex set of reactions by the Welsh Government to changing political and economic circumstances, encapsulated in a growing divergence between Welsh and central government policy ethos, notably after the 2010 election. This came alongside the close involvement of the Welsh statutory sector which was, and still is, entrenched within a New Public Management culture not easily or willingly aligned with the principles of capacity building, empowerment or community-led approaches integral to community development. The role and nature of the Welsh Government in this context is therefore inconsistent and, at times, unclear.

While the erosion of the programme design was virtually complete towards its end, some small spaces of practice held onto the original policy ethos and was not captured formally by the Welsh Government. It was driven by a small but significant number of community development practitioners and activists working outside (as well as inside) the increasingly prescriptive demands of the programme. Our evidence suggests that this was strongest in areas wherethe programme was delivered by community grounded organisations with historical ties and accountabilities to the places they worked, as predicted 16 years earlier by Adamson et al. (2001) at policy design. Indeed, where the founding participatory principles of the programme - empowerment, capacity building and the three thirds principle - were able to flourish (by skilful staff or facilitatory organisations), they proved to be crucial building blocks to more meaningful community action. However, when those principles were compromised, as in most cases under study, it led to power imbalances and exacerbated tensions at local level.

These changes have wider implications for our understanding of devolved social policy and the limits of decentralisation of power, as well as for policy. Whilst the alignment between political ideology and policy in thiscase study was momentary, it does throw into sharp relief the scale of the challenges that need to be met in order to deliver the promised benefits of devolution and decentralisation. These are often promoted as the creation of a closer interface between state and society, built on a greater distribution of power capable of delivering a more targeted and tailored policy approach, better able to reflect national culture and identity (Bogdanor, 1999; Davies, 1999). The tendency for such community programmes to deviate from their design due to a complex combination of factors - including political pragmatism, financialisation (Aalbers, 2015) and internal/external political forces which in this case includes the Coalition and Conservative Government austerity agenda - reflects a move away from an ideology shaping not only the policy but the newly established Welsh Government as an institution. We argue that the derailment of these promises of devolution through pragmatic justifications and decisions indicates the dominance of and challenges to opposing ideologies.

In terms of policy relevance, 'community' as a place based concept has faded from Welsh Government anti-poverty rhetoric in recent times, evidenced by its absence from the Social Services and Well-being Act (2014) and the Wellbeing of Future Generations Act (2015), where 'the third sector' and 'communities of interest' are respective target partners for policy engagement and delivery. Anti-poverty work is being reconceptualised, away from its presentation as a phenomenon amenable to addressing on a small scale or community level to a greater focus on regional approaches, as seen in the recent promotion of a Foundational Economy. However, current First Minister Mark Drakeford 
has re-emphasised the ideologies laid out in Chaney and Drakeford (2004) based on universalism, equality of outcome and cooperation for the common good. In this context, we would emphasise the value of Communities First's vision to involve "community experts' in a meaningful way, to empower and to build capacity. Furthermore, that the programme was deemed a failure based on arbitrary and retrospective indicators around 'eliminating poverty' does not necessarily reflect a design fault; rather, in large part, a rushed implementation which went against policy recommendations. Communities First's key lesson, therefore, is not to avoid ideologically 'soft' approaches to anti-poverty strategy in a social democratic intentioned state, but rather to learn from im plementation challenges emanating from the misalignment between vision, implementation and accountability frameworks-and in doing so to improve and refine, rather than reject.

Conceptually, our examination of one moment of alignment, and our analysis of its misalignment through dissonant implementation and monitoring practices, contributes to debates about devolution and decentralisation. Specifically, the notion holds value for any exploration into the way in which newly created, devolved states implement ideological policy visions which go against both internal restraints (limited powers) and external, dominant ideologies that permeate the wider governance field. Through unpicking the tensionsand complexities apparent in the process of devolution using one case study, we go some way towards understanding the struggles faced by other ideologically driven movements for political change as they become part of a constitutional process of state creation.

In future, cases charting the course of devolved movements through social policy design could draw on the notion of a moment, which serves as a valuable starting point from which to expand upon the fate of devolved political ideology in the face of constitutional change and power.

* Correspondence address: Dr Sioned Pearce, 38 Park Place, Cardiff, Cf10 3BB. Email: pearces11@cardiff.ac.uk

\section{Notes}

1 The executive functions of the institution became known as the 'Welsh Assembly Government' (WAG) in 2002 and the 'Welsh Government' (WG) in 2007, following the implementation of the Government of Wales Act 2006. This formally separated the legislative (National Assembly for Wales) and executive (Welsh Government) functions of devolved governance.

2 For the latest, as yet unpublished, research Pearce, Elliott and Frayne conducted 24 interviews with Communities First development workers and policy makers as the programme was coming to an end. The study looks specifically at the role of the programme's monitoring and evaluation systems over 16 years, how they changed and what impact such changes had on those involved.

3 New Deal for Communities had 39 partnerships encompassing an average population of 10,000, compared to 140 Communities First partnerships with an average population of 4,000. New Dealfor Communities was funded approximately $£ 2$ billion over 10 years, Communities First around $£ 200$ million over 17 years. New Deal for Communities had six key indicators: worklessness; crime; health; education and skills; housing and the physical environment, Communities First has six arguably 'softer' vision frameworks: Child Poverty; Environment; Community Safety; Jobs Business and Income Generation; Education Training and Skills; and Health and Wellbeing. 
${ }^{4}$ Communities Next was the title of the consultation predicating the change, the title of the programme remained Communities First.

5 For the first 10 years of the programme partnerships submitted a monitoring form to Welsh Government each May completed in a Word document with a rough template. Under the new monitoring system from 2010 partnerships had to submit an annual set of numbers to be added to a spreadsheet by Welsh Government. The sheet contained a breakdown of six 'vision framework' headings under which each partnership had to show achievements according to coded performance indicator: Child Poverty, Environment, Community Safety, Jobs Business and Income Generation, Education Training and Skills and Health and Wellbeing.

\section{References}

Adamson, D. and Bromiley, R. (2008) Community empowerment in practice: lessons from Communities First. York: Joseph Rowntree Foundation. Available at: https://www.jrf.org.uk/report/community-empowerment-practice-lessonscommunities-first

Adamson, D., Dearden, H. and Castle, B. (2001) Community Regeneration. Best Practice Review. Cardiff: National Assembly for Wales.

AMION Consulting Limited and Old Bell 3 Limited (2011) The evaluation of Communities First. Cardiff: Welsh Government.

Aalbers, M. (2015) The potential for financialisation. Dialogues in Human Geography, 5, 4, 214-219.

Armstrong, H.W. and Wells, P. (2006) Structural funds and the evaluation of community economic development initiatives in the UK: a critical perspective. Regional Studies, 40, 2, 259-272.

BBC News (2017) Anti-poverty scheme Communities First axed by minister. BBC News, [online] Available at: https://www.bbc.co.uk/news/uk-wales-politics-38972689 [Accessed: 01/05/20]

Beatty, C. and Fothergill, S. (2013) The uneven impact of welfare reform: the financial losses to places and people. Sheffield: Centre for Regional, Economic and Social Research (CRESR).

Beatty, C. and Lawless, P. (2013) Exploring change in local regeneration areas: evidence from the New Deal for Communities Programme in England. Urban Studies, 50, 5, 942-958.

Beatty, C., Foden, M., Lawless, P. and Wilson, I. (2010) Area based regeneration partnerships and the role of central government: The New Deal for Communities Programme in England. Policy and Politics, 38, 2, 235-251.

Beynon, H., Davies, R. and Davies, S. (2012) Sources of variation in trade union membership across the UK: the case of Wales. Industrial Relations Journal, 43, 3, 200-221.

Birrell, D. (2009) The impact of devolution on social policy. London: Policy Press.

Blakely, H. (2011) "A second chance at life": labour, love and welfare on a South Wales estate. PhDThesis, Cardiff University.

Bogdanor, V. (1999) Devolution in the United Kingdom. Oxford: Oxford University Press.

Bristow, G., Entwistle, T., Hines, F. and Martin, S. (2008) New Spaces for Inclusion? Lessons from the 'Three-Thirds' Partnerships in Wales. International Journal of Urban and Regional Research, 32, 4, 903-921.

Cambridge Policy Consultants (2006) Interim Evaluation of Communities First: Final Report. Cardiff: NAfW. 
Chaney, P. (2002) Social capital and the participation of marginalized groups in Government: a study of the statutory partnership between the third sector and devolved Government in Wales. Public Policy and Administration, 17, 4, 20-38.

Chaney, P. (2016) Devolution and Public Policy-making. Chapter 17. In: P. Alcock, T. Haux, M. May and S. Wright (eds) The Student's Companion to Social Policy, 5th Edition.London: John Wiley.

Chaney, P. and Drakeford, M. (2004) The primacy of ideology: social policyand the first term of the National Assembly for Wales. In: Ellison, N., Powell, M. and Bauld, L. eds. Social Policy Review. Vol. 16. Bristol: Policy Press, 121-143.

Chaney, P. and Wincott, D. (2014) Envisioning the third sector's welfare role: Critical discourse analysis of 'post-devolution' public policy in the UK 1998-2012. Social Policy and Administration, 48, 7, 757-781.

Children in Wales (2008) Communities Next - Consultation on the future of the Communities First Programme. Available at: www.childreninwales.org.uk/news/news-archive/communities-next-consultationon-the-future-of-the-communities-first-programme-300108-w/ [Accessed: 30.10.17]

Coleman, J. (2009) Communities First. Cardiff: Welsh Audit Office.

Davies, J. S. (2002) Regeneration partnership under New Labour: a case of creeping centralisation. In: Glendinning, C., Powell, M. and Rummery, K. (eds) Partnerships, New Labourand the Governance of Welfare. Bristol: Policy Press, 167-182.

Davies, R. (1999) Devolution: a process not an event. Cardiff: Institute of Welsh Affairs.

Davies, N. and Williams, D. (2009) Clear Red Water: Welsh devolution and socialist politics. London: Francis Boutle Publishers.

Dicks, B. (2014) Participatory community regeneration: a discussion of risks, accountability and crisis in devolved Wales. Urban Studies, 51, 5, 959-977.

Drakeford, M. (2006) Health policy in Wales: Making a difference in conditions of difficulty. Critical Social Policy, 26, 3, 543-561.

Driver, S. and Martell, L. (1997) New Labour's communitarianism. Critical Social Policy, 17, 27-46.

Driver, S. and Martell, L. (1999) New Labour: Culture and Economy. Chapter 11. In: L. Ray and A. Sayer (eds), Culture and Economy after the Cultural Turn. London: SAGE: 246-269.

Elliott, E., Cohen, S. and Frayne, D. (2020) The Role of Community Anchor organisations in regulating for engagement in a devolved government setting. In: McDermont, M., Cole, T., Newman, J. and Piccini, A. (eds.) Imagining Regulation Differently: CoCreating Regulation for Engagement. Bristol: Policy Press.

Etzioni, A. (1993) The Spirit of Community: Rights, Responsibilities, and the Communitarian Agenda. New York: Crown Publishers.

Etzioni, A. (1996a) The New Golden Rule: Community and Morality in a Democratic Society. New York: Basic Books/Harper Collins.

Etzioni, A. (1996b) The Responsive Community: a Communitarian Perspective. American Sociological Review, 61, 1, 1-11.

Fairclough, N. (2002) New Labour, New Language? UK: Psychology Press.

First Minister (2001) Fulfilling Policies 'Putting Wales First'. National Assembly for Wales Plenary Record of Proceedings. National Assembly for Wales. Available at: http://senedd.assembly.wales/ieListMeetings.aspx?Committeeld=401 [Accessed: 01/05/20]

Gallego, R. and Subirats, J. (2012) Spanish and regional welfare systems. Policy innovation and multi-level governance. Regional and Federal Studies, 22, 3, 269 288.

Geddes, M. (2006) Partnership and the limits to local governance in England: Institutionalist analysis and neoliberalism. International Journal of Urban and Regional Research, 30, 1, 76-97. 
Giddens, A. (1998) The Third Way: The Renewal of Social Democracy. Cambridge: Polity Press.

Giddens, A. (2000) The Third Way and its Critics. Cambridge: Polity Press.

Glendinning, C., Dowling, B. and Powell, M. (2005) Partnerships between health and social care under "New Labour": smoke without fire? A review of policy and evidence. Evidence and Policy, 1, 3, 365-82.

Greer, S. (2010) How does decentralisation affect the welfare state? Territorial politics and the welfare state in the UK and US. Journal of Social Policy, 39, 2, 181-201.

Hale, S. (2004) The communitarian 'philosophy' of New Labour. In: S. Hale, W. Legget and L. Martell (eds) The Third Way and Beyond: Criticisms, futures, alternatives. Manchester: Manchester University Press: 87-107.

Hamilton, M. (2011) Unruly practices: what a sociology of translations can offer to educational policy analysis. Educational Philosophy and Theory, 43, s1, 55-75.

Hincks, S. and Robson, B. (2010) Regenerating Communities First Neighbourhoods in Wales. York: Joseph Rowntree Foundation.

Hoggett, P. (1996) New modes of control in the public service. Public Administration, 74, $1,9-32$.

Hood C. (1991) A Public Management for all Seasons? Public Administration, 69, 1, 319.

Imrie, R and Raco, M. (2003) Community and the changing nature of urban policy. Chapter 1 in: R. Imrie and M. Raco (eds), Urban Renaissance? New Labour, Community and Urban Policy. Bristol: The Policy Press: 3-36.

Ipsos MORI and Wavehill Consulting (2015) Communities First: Process Evaluation. Cardiff:WG.

Jones, M. and MacLeod, G. (2004) Regional spaces, spaces of regionalism: Territory, insurgent politics and the English question. Transactions of the Institute of British Geographers, 29, 4, 433-452.

Jones, R., Goodwin, M., Jones, M. and Pett, K. (2005) 'Filling in' the state: economic governance and the evolution of devolution in Wales. Environment and Planning C: Government and Policy. 23, 337-360.

Lawless, P., Foden, M., Wilson, I. and Beatty, C. (2009) Understanding Area-based Regeneration: The New Deal for Communities Programme in England. Urban Studies, 42, 2, 257-275.

Levitas, R. (2005) The Inclusive Society? Social Exclusion and New Labour (2nd edn), Basingstoke: Palgrave Macmillan.

Lund, B. (1999) 'Ask not what your community can do for you': obligations, New Labour and welfare reform. Critical Social Policy, 19, 4, 447-462.

Mooney, G. and Poole, L. (2004) ‘A land of milk and honey'? Social policy in Scotland after Devolution. Critical Social Policy, 24, 4, 458-483.

National Assembly for Wales (2017) Communities First: lessons learnt. Cardiff: NAfW.

Newman, J. (2001) Modernising Governance: New Labour, Policy and Society. London: SAGE.

Ohmae, K. (1995) The End of the Nation State: the rise of regional economies. New York: The Free Press.

Osmond, J. (1999) Adrift but afloat: the civil service and the National Assembly. Cardiff: Institute for Welsh Affairs.

Pearce, S. (2012) Constitutional change and community development: Communities First under the Welsh Government. Sheffield: Centre for Regional, Economic and Social Research, Sheffield Hallam University.

Pill, M. (2012) Neighbourhood initiatives in Wales and England: shifting purposes and changing scales. People, Place and Policy, 6, 2, 76-89.

Pill, M. and Guarneros-Meza, V. (2017) Local governance under austerity: hybrid organisations and hybrid officers. Policy and Politics, 46, 3, 409-425. 
Power, M. (1999) The Audit Society: Rituals of Verification. Oxford: Oxford University Press.

Prideaux, S. (2005) Not So New Labour: A Sociological Critique of New Labour's Policy and Practice. Bristol: Policy Press.

Rhodes, R.A.W. (1997) Understanding Governance: policy networks, governance, reflexivity and accountability. Buckingham: Open University Press.

Rhodes, R.A.W. (2011) Everyday Life in British Government. Oxford: Oxford University Press.

Richard Commission (2004) Report of the Richard Commission: Commission on the Powers and Electoral Arrangements of the National Assembly for Wales. Commission on Devolution in Wales.

Roberts, J.M. and Devine, F. (2003) The Hollowing Out of the Welfare State and Social Capital. Social Policy and Society. 2, 4, 309-318.

Royles, E. (2007) Revitalising democracy: devolution and civil society in Wales. Cardiff: University of Wales Press.

Schofield, B. (2002) Partners in Power: Governing the Self-Sustaining Community. Sociology, 36, 3, 663-683.

Scott, G. and Wright, S. (2012) Devolution, social democratic visions and policy reality in Scotland. Critical Social Policy, 32, 3.

Sellers, J. M. and Lidström, A. (2007) Decentralization, Local Government, and the Welfare State. Governance, 20,609-632.

Sheeley, A. (2012) Devolution and welfare reform: Re-evaluating ‘success'. Social Work, $57,4,321-331$.

Silk Commission (2012) Empowerment and Responsibility: Financial Powers to Strengthen Wales. Cardiff: Commission on Devolution in Wales.

Sophocleous, C. (2009) Exploring Discourses of Partnership Among Regeneration Policy Elites: A Case Study From Wales, MSc Dissertation: Cardiff University.

Sophocleous, C. (2014) Mediations and Manipulations: Everyday Community Partnership Making in South Wales. PhD Thesis. Cardiff: Cardiff University.

Sullivan, H. and Skelcher, C. (2002) Working Across Boundaries: Collaboration in Public Services. Basingstoke: Palgrave Macmillan.

Sum, N. and Jessop, B. (2013) Towards a Cultural Political Economy: putting culture in its place. London: Edward Elgar.

Taylor, M. (2003) Public Policy in the Community. Basingstoke: Palgrave Macmillan.

Vampa, D. (2014) Territorial mobilization and sub-state welfare governance in Italy and Spain: Comparing four regional case studies. Paper circulated at the 2014 ECPR conference, Glasgow. Available at: https://pdfs.semanticscholar.org/f572/ef631398afc48a00797b910b46e0448e 10a7.pdf? ga $=2.121160783 .614840063 .1588328513-$ 1365314975.1588328513 [Accessed:01/05/20]

Vedung, E. (2017) Public Policy and Program Evaluation. New York: Routledge.

Wavehill Consulting (2007) Evaluation of the Communities First Trust Fund. Cardiff: WG.

Welsh Assembly Government (2000) Regenerating our most deprived communities. Cardiff: WAG.

Welsh Assembly Government (2001) Communities First Baseline Report. Cardiff: WAG.

Welsh Assembly Government (2002a) Communities First Guidance; August 2002. Cardiff: WAG.

Welsh Assembly Government (2002b) Communities First Guidance; First Revision October2002. Cardiff: WAG. 